\title{
Severity of illness and the weekend mortality effect: a retrospective cohort study
}

\author{
Eric Bressman ${ }^{1 *}\left(\mathbb{D}\right.$, John C. Rowland ${ }^{2}$, Vinh-tung Nguyen ${ }^{1}$ and Beth G. Raucher ${ }^{1}$
}

\begin{abstract}
Background: Weekend admission to the hospital has been found to be associated with higher in-hospital mortality rates, but the cause for this phenomenon remains controversial. US based studies have been limited in their characterization of the weekend patient population, making it difficult to draw conclusions about the implications of this effect.

Methods: A retrospective cohort study, examining de-identified, patient level data from 2015 to 2017 at US academic medical centers submitting data to the Vizient database, comparing demographic and clinical risk profiles, as well as mortality, cost and length of stay, between weekend and weekday patient populations. Between-group differences in mortality were assessed using the chi-square test for categorical measures and Wilcoxon rank-sum test for continuous measures. Logistic regression models were used to test the multivariate association of weekend admission and other patient-level factors with death, LOS, etc.
\end{abstract}

Results: We analyzed 10,365,605 adult inpatient encounters. Within the weekend patient population, 30.6\% of patients were categorized as having either a major or extreme risk of mortality on admission, as compared to $23.7 \%$ on weekdays ( $p<$ 0.001). We found a significantly increased unadjusted mortality rate associated with weekend admission (OR 1.46; $95 \% \mathrm{Cl}$ 1.45-1.47) which was substantially attenuated after adjusting for disease severity and other demographic covariates, though remained significant (OR 1.05; 95\% Cl 1.04-1.06). In the subgroup of non-elective admissions, the unadjusted OR for death was 1.14 (95\% Cl 1.13-1.15), and the adjusted OR was $1.04(95 \% \mathrm{Cl} 1.03-1.05)$. Weekend admission was associated with a longer median LOS ( 4 vs 3 days in the weekday group; $p<0.01$ ), but a lower median cost ( $\$ 8224$ vs $\$ 9999$ dollars in the weekday group; $p<0.01$ ).

Conclusion: The patient population admitted on weekends is proportionally higher risk than the population admitted on weekdays, and the observed weekend mortality effect is largely attributable to this risk imbalance.

Keywords: Weekend mortality, Weekend admission, Severity of illness

\section{Background}

The weekend mortality effect- whereby patients admitted to the hospital on the weekend have a higher mortality rate than those admitted on weekdays- is a welldescribed, albeit controversial, topic in the literature.

\footnotetext{
* Correspondence: eric.bressman@icahn.mssm.edu

'Department of Medicine at Mount Sinai, 1 Gustave L Levy PI, New York, NY 10128, USA

Full list of author information is available at the end of the article
}

This association has been identified in several observational studies [1-7] and meta-analyses, [8,9] ranging from broad population datasets to specialty and disease specific groups, though there are notable negative studies $[10,11]$. The relative increased risk of death for weekend admission has varied across datasets, but has typically fallen between 10 and $20 \%[9,12]$.

A particular point of contention has surrounded the root cause of the weekend mortality effect, with the

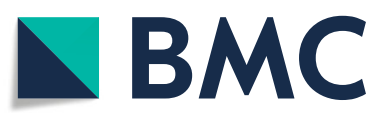

(c) The Author(s). 2020 Open Access This article is licensed under a Creative Commons Attribution 4.0 International License, which permits use, sharing, adaptation, distribution and reproduction in any medium or format, as long as you give appropriate credit to the original author(s) and the source, provide a link to the Creative Commons licence, and indicate if changes were made. The images or other third party material in this article are included in the article's Creative Commons licence, unless indicated otherwise in a credit line to the material. If material is not included in the article's Creative Commons licence and your intended use is not permitted by statutory regulation or exceeds the permitted use, you will need to obtain permission directly from the copyright holder. To view a copy of this licence, visit http://creativecommons.org/licenses/by/4.0/. The Creative Commons Public Domain Dedication waiver (http://creativecommons.org/publicdomain/zero/1.0/) applies to the data made available in this article, unless otherwise stated in a credit line to the data. 
prevailing lines of thought falling into either patient extrinsic (reduced weekend staffing, increased delays in time to necessary procedures, etc.) $[9,13,14]$ or patient intrinsic (severity of illness, number of comorbidities, etc.) factors $[15,16]$. Prior studies have been limited in their characterization of the weekend patient population, largely due to limitations of datasets [17]. For this reason the question remains unresolved.

The purpose of the present study was to examine the outcomes of weekend admissions in a large subset of US academic hospitals, while taking into account the unique features of the individual patients. We conducted a retrospective cohort study, investigating patient level characteristics and outcomes of weekend versus weekday admissions across a nationally representative sample of US academic medical centers.

\section{Methods}

\section{Data source}

We obtained patient level data from in-hospital admissions for academic hospitals submitting data to the Vizient clinical database between January 2015 and December 2017. (encompasses 106 academic hospitals across 39 states and Washington DC). Vizient maintains a clinical database which contains discharge and patient-level detail from member institutions. Member institutions submit data to the clinical database on a regular basis, primarily consisting of administrative billing records, supplemented by value-added data from Vizient such as clinical flags and $3 \mathrm{M}$ grouper values for APR-DRG, severity of illness, and risk of mortality (see below).

All adult admissions (age 18 and older) were included for the primary outcome analysis. Subsequent analyses for both the primary outcome as well as secondary outcomes were conducted on the subgroup of non-elective admissions out of concern for unmeasured confounding. We excluded cases with an admission status documented as newborn or UHC service line code indicating either neonatology or normal newborns (935 cases, 76 cases and 25 cases, respectively), and all cases that did not have a risk of mortality or severity of illness specified (6984 cases). A small number of patient IDs had a mortality documented in more than one encounter (363 patients, $<0.01 \%$ of all encounters; 370 additional deaths); in these cases we included the last encounter and excluded the excess deaths.

Since we did not have a time of admission, patients were grouped according to day of admission, with weekend admission defined as patients admitted from midnight Friday to midnight Sunday $[1,2]$.

\section{Outcome measures}

The primary outcome examined was in-hospital mortality, which is registered in Vizient based on coding of discharge status. Secondary outcomes included length of stay (LOS), total cost (direct and indirect) of admission, and hospital acquired conditions (HACs). Direct cost are those related to patient care, while indirect costs incorporate capital and building costs. Vizient provides an estimated direct cost by using a ratio of cost to charges combined with detailed patient charges submitted by member institutions. This ratio is based on the 2017 risk adjustment model, which incorporates the calculation of a hospital specific wage index to adjust for labor differences across the country. HACs are as defined by CMS, and include vascular catheter associated infection, catheter associated urinary tract infections, and stage 3 and 4 pressure ulcers, among others. The complete list can be found on the CMS website (https:// www.cms.gov/medicare/medicare-fee-for-service-payment/ hospitalacqcond/hospital-acquired_conditions.html).

\section{Independent variables}

Analysis of outcomes took into account illness severity and risk of mortality at the time of admission. Illness severity and risk of death were defined as minor, moderate, major or extreme, based on the $3 \mathrm{M}$ All Patients Refined Diagnosis Related Groups (APR-DRG) grouper. These $3 \mathrm{M}$ levels are based on a proprietary algorithm. The variable inputs into the algorithm are patient age, sex, primary admission diagnosis (for medical patients) or procedure (for surgical patients), and secondary diagnoses/conditions. Based on these indices, $3 \mathrm{M}$ has constructed, and subsequently validated, separate scales for severity of illness (defined as the extent of physiologic decompensation or organ system loss of function) and risk of mortality (likelihood of dying). Other patient characteristics included age, sex, number of comorbidities, race, ethnicity, primary payer (Medicare, Medicaid, commercial insurance, or other), and admission status (emergency, urgent, elective, trauma).

\section{Analysis}

Between-group differences in mortality were assessed using the chi-square test for categorical measures and Wilcoxon rank-sum test for continuous measures. Logistic regression models were used to test the multivariate association of weekend admission and other patient-level factors with death, LOS, etc.. All statistical analyses were conducted in SAS version 9.4 (SAS Institute, Cary, North Carolina).

Because our study used de-identified patient data, available to all members of the Vizient database, our study was determined by the institutional review board to be not human subjects research, and therefore did not require further review.

\section{Results}

Our analysis included 10,365,605 adult inpatient encounters for $6,777,415$ patients at academic hospitals. Of these encounters, 8,408,723 (81.1\%) occurred between Monday and Friday, while 1,956,882 (18.9\%) occurred on the weekend (Saturday or Sunday). 


\section{Demographics}

The weekend patient population was slightly younger (median age 55.7 vs. 57.2 in the weekday group; $p<$ 0.001) (Table 1). It had proportionally more selfidentified black ( $24.7 \%$ vs. $21.6 \% ; p<0.001)$ and Hispanic $(9.5 \%$ vs $8.7 \% ; p<0.001)$ patients, and fewer selfidentified white patients $(60.1 \%$ vs $64.1 \%$; $p<0.001)$. Patients admitted on weekends were also more likely to have Medicaid $(23.6 \%$ vs $20.6 \% ; p<0.001)$ and less likely to have private insurance $(26.5 \%$ vs. $31.0 \% ; p<0.001)$.

Patients admitted on weekends were also more likely to have markers of poor health status than those admitted during weekdays. The mean number of comorbidities was slightly higher $(2.7[+/-2.1]$ vs $2.4[+/-2.0] ; p<0.001)$; a higher proportion of patients had a severity of illness categorized as major or extreme $(44.7 \%$ vs $37.4 \%$; $p<0.001)$ and a mortality risk categorized as major or extreme (30.6\% vs $23.7 \% ; p<0.001)$. There were proportionally more urgent and emergent admissions $(88.0 \%$ vs $66.6 \%$ in the weekday group; $p<0.001$ ), and fewer elective admissions $(8.3 \%$ vs $31.4 \%$ in the weekday group; $p<0.001)$.

\section{Primary outcome}

There were a total of 250,953 deaths $(2.4 \%$ of encounters; $3.7 \%$ of individuals) reported across all encounters. Of these, 187,822 (2.2\% of encounters) occurred on weekdays and 63,131 (3.2\% of encounters) on weekends (crude OR of 1.46; 95\% CI 1.45-1.47) (Table 2). After multivariate adjustment for severity of illness, risk of mortality, number of comorbidities, and demographics this relationship was attenuated, though remained significant (OR 1.05; 95\% CI 1.04-1.06).

Specific patient-level factors that were significantly associated with death were risk of mortality (AOR 1.07, 95\% CI 1.06-1.08), and admission status (AOR of 1.08, 95\% CI 1.07-1.09).

\section{Subgroup analysis}

In the subgroup of patients non-electively admitted, there were a total of 7,559,722 encounters for 4,942,479 patients. There were a total of 236,796 deaths $(3.1 \%$ of encounters, $4.8 \%$ of individuals) reported across these encounters. Of these, 174,998 (3.0\% of encounters) occurred on weekdays and 61,798 (3.4\% of encounters) on weekends (crude OR of 1.14; 95\% CI 1.13-1.15) (Table 3). After multivariate adjustment for severity of illness, risk of mortality, number of comorbidities, and demographics this relationship was attenuated, though remained significant (OR 1.04; 95\% CI 1.03-1.05).

\section{Secondary outcomes Length of stay}

Median length of stay in the overall population was longer for patients admitted on weekends at 4 days (median
IQR [2-7]) versus 3 days (median IQR [2-6]) for the weekday group $(p<0.001)$ (Table 4$)$. Median length of stay in the group of patients admitted non-electively was similar for patients admitted on weekends (4 days, median IQR [2-7]) and weekdays (4 days, median IQR [2-6]) $(p<$ 0.001) (Table 4). After multivariate adjustment, and excluding encounters that resulted in death, the length of stay was shorter for patients admitted on weekends (difference, -2.87 , 95\% CI: $-3.06,-2.69 \%, p<0.001$ ).

\section{Cost}

Median cost in the overall population was $\$ 8224$ for the weekend group (median IQR [4732 - 16,696]) and \$9999 for the weekday group (median IQR [5459 - 19,247]) $(p<$ $0.001)$. Median cost in the group of patients admitted nonelectively was $\$ 8348$ for the weekend group (median IQR $[\$ 4755$ - $\$ 16,900])$ and $\$ 8639$ for the weekday group (median IQR [ $\$ 4831-\$ 17,361])(p<0.001)$ (Table 4). After multivariate adjustment, total cost in the weekend admission group was slightly less than that in the weekday group (difference, $-0.97,95 \%$ CI: $-1.19,-0.76 \%, p<0.001$ ).

\section{Hospital acquired conditions}

Of the cases reporting on occurrence of HACs, 99.7\% reported no HAC in both the weekend and weekday admission groups. There were a total of 22,423 HACs, accounting for $0.30 \%$ of all admissions. HAC rates were equivalent in the weekend $(0.30 \%)$ and weekday $(0.30 \%)$ admission groups $(p=0.02)$.

\section{Discussion}

In this study of over 10 million hospital admissions in US academic medical centers in 39 states, patients admitted on weekends had a higher risk of death than those admitted on weekdays. While we found a significant, unadjusted increased risk of mortality associated with weekend admission (odds ratio of 1.46), after adjusting for patient risk profile and demographics, this was attenuated to a much more modest, though still significant, effect (odds ratio 1.05). Our findings were similar when looking at the subgroup of nonelectively admitted patients (AOR 1.04). This result suggests that the observed weekend mortality effect in US academic medical centers is largely a product of the unique demographic and risk profile of the weekend patient population, a conclusion that many earlier studies did not reach, $[2,5]$ and only recently has gained traction $[15,16,18]$. We found a significant difference in the patient risk pool, with the weekend population consisting of proportionally higher risk patients; correspondingly, the largest confounding effect was seen when adjusting for patient admission risk of mortality.

We also found several other unique features of the weekend patient population, including a greater proportion of Medicaid insured patients and a greater proportion of patients that self-identified with historically underserved 
Table 1 Patient Characteristics

\begin{tabular}{|c|c|c|c|}
\hline \multirow[t]{2}{*}{ Characteristics } & $\begin{array}{l}\text { Monday through Friday } \\
(\boldsymbol{N}=8,408,723)\end{array}$ & $\begin{array}{l}\text { Weekend (Saturday/Sunday) } \\
(\boldsymbol{N}=1,956,882)\end{array}$ & \multirow[t]{2}{*}{$\boldsymbol{p}$-value } \\
\hline & $\%$ or Median [IQR] & \multirow{2}{*}{\multicolumn{2}{|c|}{$\%$ or Median [IQR] }} \\
\hline \multicolumn{2}{|l|}{$\overline{\text { Age }}$} & & \\
\hline Median & $57.2[38.9-69.5]$ & $55.7[36.1-69.9]$ & $<0.001$ \\
\hline \multicolumn{4}{|l|}{ Sex } \\
\hline Male & $45.6 \%$ & $46.0 \%$ & $<0.001$ \\
\hline Female & $54.4 \%$ & $54.0 \%$ & $<0.001$ \\
\hline Unknown & $<0.01 \%$ & $0.01 \%$ & $<0.001$ \\
\hline \multicolumn{4}{|l|}{ Race } \\
\hline White & $64.1 \%$ & $60.1 \%$ & $<0.001$ \\
\hline Black & $21.6 \%$ & $24.7 \%$ & $<0.001$ \\
\hline Asian & $2.8 \%$ & $2.9 \%$ & $<0.001$ \\
\hline Other & $9.1 \%$ & $9.7 \%$ & $<0.001$ \\
\hline Unknown/Unavailable/Declined & $2.5 \%$ & $2.6 \%$ & $<0.001$ \\
\hline \multicolumn{4}{|l|}{ Ethnicity } \\
\hline Hispanic & $8.7 \%$ & $9.5 \%$ & $<0.001$ \\
\hline Non-Hispanic & $76.6 \%$ & $76.6 \%$ & $<0.001$ \\
\hline Unknown/Not Reported/Unavailable/Declined & $14.7 \%$ & $13.9 \%$ & $<0.001$ \\
\hline \multicolumn{4}{|l|}{ Primary Payer } \\
\hline Commercial & $31.0 \%$ & $26.5 \%$ & $<0.001$ \\
\hline Medicaid & $20.6 \%$ & $23.6 \%$ & $<0.001$ \\
\hline Medicare & $40.4 \%$ & $40.5 \%$ & $<0.001$ \\
\hline Other & $8.1 \%$ & $9.4 \%$ & $<0.001$ \\
\hline \multicolumn{4}{|l|}{ Admission Risk of Mortality } \\
\hline Minor & $48.8 \%$ & $42.4 \%$ & $<0.001$ \\
\hline Moderate & $27.5 \%$ & $27.0 \%$ & $<0.001$ \\
\hline Major & $18.0 \%$ & $21.9 \%$ & $<0.001$ \\
\hline Extreme & $5.7 \%$ & $8.7 \%$ & $<0.001$ \\
\hline \multicolumn{4}{|l|}{ Admission Severity of Illness } \\
\hline Minor & $24.0 \%$ & $19.0 \%$ & $<0.001$ \\
\hline Moderate & $38.7 \%$ & $36.3 \%$ & $<0.001$ \\
\hline Major & $29.2 \%$ & $33.5 \%$ & $<0.001$ \\
\hline Extreme & $8.2 \%$ & $11.2 \%$ & $<0.001$ \\
\hline \multicolumn{4}{|l|}{ Admission Status } \\
\hline Emergency & $49.0 \%$ & $70.2 \%$ & $<0.001$ \\
\hline Urgent & $17.6 \%$ & $17.8 \%$ & $<0.001$ \\
\hline Elective & $31.4 \%$ & $8.3 \%$ & $<0.001$ \\
\hline Trauma Center & $1.6 \%$ & $3.3 \%$ & $<0.001$ \\
\hline Info not available & $0.3 \%$ & $0.4 \%$ & $<0.001$ \\
\hline \multicolumn{4}{|l|}{ Number of Comorbidities } \\
\hline Median & $2[1-4]$ & $2[1-4]$ & $<0.001$ \\
\hline Mean & 2.4 & 2.7 & $<0.001$ \\
\hline
\end{tabular}


Table 2 Primary Outcome

\begin{tabular}{|c|c|c|c|c|c|}
\hline \multirow[t]{2}{*}{$\begin{array}{l}\text { Primary } \\
\text { Outcome }\end{array}$} & $\begin{array}{l}\text { Monday through Friday } \\
(\boldsymbol{N}=8,408,723)\end{array}$ & $\begin{array}{l}\text { Weekend (Saturday/Sunday) } \\
(\boldsymbol{N}=1,956,882)\end{array}$ & $\begin{array}{l}\boldsymbol{p} \text { - } \\
\text { value }\end{array}$ & $\begin{array}{l}\text { Crude OR* } \\
(95 \% \mathrm{Cl})\end{array}$ & $\begin{array}{l}\text { Adjusted OR } \\
(95 \% \mathrm{Cl})\end{array}$ \\
\hline & n (\%) & n (\%) & & & \\
\hline Death & $187,822(2.2)$ & $63,131(3.2)$ & $<0.001$ & $1.46(1.45-1.47)$ & $1.05(1.04-1.06)$ \\
\hline
\end{tabular}

minority groups (in particular black and Hispanic). The magnitude of all of these demographic differences is relatively small, but may reflect challenges in access to non-hospital based care over the weekends in these groups.

Our study builds on other recent work that has begun to call into question the nature of the weekend mortality effect internationally [15] and in the US [18]. Ko et al. conducted a similar analysis on a cohort from the $\mathrm{Na}$ tional Inpatient Sample and found a risk adjusted odds ratio of 1.029 (95\% CI, 1.020-1.039; $P<.0001$ ), which, while significant, was a smaller effect size than seen in other settings, and in line with what we found. The notable discrepancies in our findings pertain to the unique characteristics of the weekend patient population described above- they did not find as pronounced a difference in proportional risk of mortality or severity of illness- which may be attributed to a few factors. For one, our analysis is focused on academic medical centers, whereas theirs included non-academic hospitals. They also chose to exclude elective admissions out of concern for unmeasured confounding. While we share this concern, we conducted our analysis both with and without elective admissions included for a couple of reasons. First, we maintained elective admissions in our primary analysis due to lack of standardization across systems in classifying elective and non-elective admissions. For those systems that define elective based on referral from an outpatient source, this misses many emergent cases [19]. We also maintained all admission sources to more accurately replicate earlier work that had taken a broader, more inclusive approach [19]. Our study population closely resembles that of Freemantle et al., one of the more widely cited papers, which looked, separately, at hospitals in the UK and a large subset of academic medical centers in the US. In the latter analysis they found an adjusted hazard ratio of 1.18 ([95\% CI 1.11 to 1.26$] P<.0001)$.
There are likely several reasons for the differences in our result, some of which are highlighted by Ko et al. These include the use of Wednesday as an index day against which to compare weekend days, when there is in fact some variation in outcomes across weekdays [10]. They also limit their analysis to in-hospital deaths within 30 days of admission. Most notably, however, they lack a validated metric by which to risk stratify their population. In our study, the $3 \mathrm{M}$ severity of illness metrics allowed us to characterize a more acutely ill weekend patient population, and adjusting for this alone demonstrated a greater confounding effect than any other single covariate.

There are several potential explanations for the higher illness severity observed among weekend compared to weekday admissions. Meacock et al. [20] looked at the proportion of patients presenting to the ED that were admitted on weekends vs weekdays, finding a higher threshold of illness severity for admission on weekends. In other words, the admission triage process on weekends may simply select a sicker subset of patients. Another possibility is that patients generally avoid coming into the hospital on weekends unless they feel they must, creating a natural selection pressure for more acute patients; this, however, is not supported by Meacock's findings. There are, of course, far fewer elective admissions on weekends (in our study population, $8.3 \%$ vs. $31.4 \%$ on weekends and weekdays respectively) with most outpatient practices closed and scheduled procedures not occurring, and at face value one would expect these patients to be less acutely ill; indeed, they have a much lower mortality rate than those admitted urgently or emergently. However, admission status alone does not account for the weekend effect, further suggesting a selfselection process among those presenting on weekends.

The difference in cost between the weekend and weekday groups, though statistically significant, is quite small

Table 3 Subgroup of Non-Elective Admissions

\begin{tabular}{lllll}
\hline Outcome & $\begin{array}{l}\text { Monday through Friday } \\
(N=5,764,339)\end{array}$ & $\begin{array}{l}\text { Weekend (Saturday/Sunday) } \\
(\mathrm{N}=1,795,383)\end{array}$ & $\begin{array}{l}\boldsymbol{p} \text { - } \\
\text { value }\end{array}$ & $\begin{array}{l}\text { Crude OR* } \\
(95 \% \mathrm{Cl})\end{array}$ \\
\hline $\mathrm{n}(\%)$ & $\mathrm{n}(\%)$ & $\begin{array}{l}\text { Adjusted OR } \\
(95 \% \mathrm{Cl})\end{array}$ \\
\hline Death & $174,998(3.0)$ & $61,798(3.4)$ & $<0.001$ & $1.14(1.13-1.15)$ \\
LOS (days) & $4[2-7]$ & $4[2-6]$ & $<0.001$ & \\
Total Cost (USD) & $8639[4831-17,361]$ & $8348[4755-16,900]$ & $<0.001$ & \\
HAC (\%) & 0.3 & 0.3 & 0.02 & \\
\hline
\end{tabular}


Table 4 Secondary Outcomes

\begin{tabular}{|c|c|c|c|c|c|}
\hline \multirow[t]{2}{*}{ Secondary Outcomes } & \multicolumn{2}{|c|}{ Monday through Friday } & \multicolumn{2}{|c|}{ Weekend (Saturday/Sunday) } & \multirow{2}{*}{$\begin{array}{l}\boldsymbol{p} \text { - } \\
\text { value }\end{array}$} \\
\hline & $\begin{array}{l}\text { No. } \\
\text { Observed }\end{array}$ & Median [IQR] & $\begin{array}{l}\text { No. } \\
\text { Observed }\end{array}$ & Median [IQR] & \\
\hline LOS (days) & $8,408,721$ & $3[2-7]$ & $1,956,882$ & $4[2-6]$ & $<0.001$ \\
\hline Total Cost (USD) & $8,219,677$ & 9999 [5459 - 19,247] & $1,907,171$ & $8224[4732-16,696]$ & $<0.001$ \\
\hline Hospital Acquired Conditions & $8,408,723$ & & $1,956,882$ & & \\
\hline HAC criteria is not met & & $8,385,152(99.72)$ & & $1,951,178(99.71)$ & $<0.001$ \\
\hline One or more HAC criteria met & & $23,571(0.28)$ & & $5704(0.29)$ & $<0.001$ \\
\hline
\end{tabular}

in magnitude, and unlikely to be interpreted as meaningful. While the prior literature is conflicting on this question, $[5,18,21,22]$ our findings are in line with similarly designed studies that have taken a broader approach. Finally, the difference in LOS between the weekend and weekday groups is minimal $(2.9 \%$ shorter in the weekend group) after multivariate adjustment. There has been no clear consensus on this question across the literature, though, in general the differences between weekend and weekday groups have been similarly small [5, 8, 10, 23]. This may reflect the reality that length of stay, as an outcome, is influenced not only by patient complexity and illness factors, but also by discharge processes that often involve complex logistics and incorporate essential ancillary staff (whose services are even more dramatically reduced over weekends). Fonarow, et al., found the longest LOS associated with Thursday and Friday admissions, for example; for admissions whose median LOS is between 3 and 4 days, those admitted late in the week may suffer the most from the limited discharge coordination available on weekends [10].

Limitations of our study include the fact that, like many other studies in this space, this is a retrospective cohort study, reliant on accurate, consistent coding across many EMRs and institutions. Because our primary exposure of interest is day of admission, there is no reason to believe that any flaws in coding or documentation would affect any particular cohort more than another. For this reason, we considered as broad a population as possible in our analysis, and then stratified by, rather than excluded, various designations. While a major strength of our study is the ability to account for patient intrinsic factors, using metrics for risk of mortality and severity of illness, our dataset is limited in its inability to assess extrinsic factors, such as delays in care and reduced weekend staffing. The demographic differences we found between weekend and weekday populations comes with the caveat that EMR reporting of race and ethnicity is fraught with error, and data from retrospective studies such as ours using these variables should be interpreted with caution. Lastly, despite adjustment for a wide array of sociodemographic covariates, there is always the potential for residual confounding.

\section{Conclusion}

The weekend patient population admitted to the hospital has several unique characteristics, including a proportionally higher risk profile. The higher mortality rate seen in this group is significantly attenuated by adjusting for these factors. The demographic profile of weekend admissions to the hospital may reflect particular challenges in access to non-hospital based care on weekends in certain groups. Given that the weekend patient population is an inherently higher risk population, it is not clear that infrastructural changes related to expanded staffing will significantly impact the outcomes in this group.

\section{Abbreviations}

AOR: Adjusted odds ratio; APR-DRG: All patients refined diagnosis related groups; Cl: Confidence interval; EMR: Electronic medical record; HAC: Hospital acquired condition; LOS: Length of stay; OR: Odds ratio

\section{Acknowledgements}

Not applicable.

\section{Authors' contributions}

EB performed study design and analyzed and interpreted the data. JR performed statistical analyses and aided in interpretation of the data. VN and BR contributed to study design. All authors read and approved the final manuscript.

Funding

No funding was obtained for this study.

\section{Availability of data and materials}

The datasets used and/or analyzed during the current study are available from the corresponding author on reasonable request.

\section{Ethics approval and consent to participate}

Because our study used de-identified patient data, available to all members of the Vizient database, our study was determined by the institutional review board to be not human subjects research, and therefore did not require further review. Need for ethics approval was waived by the Mount Sinai Health System Program for the Protection of Human Subjects Institutional Review Board.

As this is a retrospective study, there is no need for consent to participate to be obtained.

\section{Consent for publication}

Not applicable.

\section{Competing interests}

The authors declare that they have no competing interests.

\section{Author details}

${ }^{1}$ Department of Medicine at Mount Sinai, 1 Gustave L Levy PI, New York, NY 10128, USA. ${ }^{2}$ Department of Population Health Science and Policy at Mount Sinai, 1425 Madison Ave, New York, NY 10128, USA. 
Received: 11 November 2019 Accepted: 24 February 2020

Published online: 04 March 2020

\section{References}

1. Bell CM, Redelmeier DA. Mortality among patients admitted to hospitals on weekends as compared with weekdays. N Engl J Med. 2001;345(9):663-8.

2. Aylin P, Yunus A, Bottle A, Majeed A, Bell D. Weekend mortality for emergency admissions. A large, multicentre study. BMJ Quality \& Safety. 2010;19(3):213-7.

3. Ricciardi R, Roberts PL, Read TE, Baxter NN, Marcello PW, Schoetz DJ. Mortality rate after nonelective hospital admission. Arch Surg. 2011;146(5):545-51.

4. Handel AE, Patel SV, Skingsley A, Bramley K, Sobieski R, Ramagopalan SV. Weekend admissions as an independent predictor of mortality: an analysis of Scottish hospital admissions. BMJ Open. 2012;2(6):e001789.

5. Nanchal R, Kumar G, Taneja A, et al. Pulmonary embolism: the weekend effect. Chest. 2012;142(3):690-6.

6. Aldridge C, Bion J, Boyal A, et al. Weekend specialist intensity and admission mortality in acute hospital trusts in England: a cross-sectional study. Lancet. 2016;388(10040):178-86.

7. An R. Impact of weekend admission on in-hospital mortality among US adults, 2003-2013. Ann Epidemiol. 2017;27(12):790-5.

8. Sorita A, Ahmed A, Starr SR, et al. Off-hour presentation and outcomes in patients with acute myocardial infarction: systematic review and metaanalysis. Bmj. 2014;348:f7393.

9. Pauls LA, Johnson-Paben R, McGready J, Murphy JD, Pronovost PJ, Wu CL. The weekend effect in hospitalized patients: a meta-analysis; 2017.

10. Fonarow GC, Abraham WT, Albert NM, et al. Day of admission and clinical outcomes for patients hospitalized for heart failure: findings from the organized program to initiate lifesaving treatment in hospitalized patients with heart failure (OPTIMIZE-HF). Circ Heart Fail. 2008;1(1):50-7.

11. Hoh BL, Chi Y-Y, Waters MF, Mocco J, Barker FG. Effect of weekend compared with weekday stroke admission on thrombolytic use, in-hospital mortality, discharge disposition, hospital charges, and length of stay in the Nationwide inpatient sample database, 2002 to 2007. Stroke. 2010;41(10):2323-8.

12. Freemantle N, Richardson M, Wood J, et al. Weekend hospitalization and additional risk of death: an analysis of inpatient data. J R Soc Med. 2012;105(2):74-84.

13. Kostis WJ, Demissie K, Marcella SW, Shao Y-H, Wilson AC, Moreyra AE. Weekend versus weekday admission and mortality from myocardial infarction. N Engl J Med. 2007;356(11):1099-109.

14. McKinney JS, Deng Y, Kasner SE, Kostis JB, Group MIDASS. Comprehensive stroke centers overcome the weekend versus weekday gap in stroke treatment and mortality. Stroke. 2011;42(9):2403-9.

15. Sun J, Girling AJ, Aldridge C, et al. Sicker patients account for the weekend mortality effect among adult emergency admissions to a large hospital trust. BMJ Qual Saf. 2019;28(3):223-30

16. Walker AS, Mason A, Quan TP, et al. Mortality risks associated with emergency admissions during weekends and public holidays: an analysis of electronic health records. Lancet. 2017:390(10089):62-72.

17. Lilford RJ, Chen Y-F. The ubiquitous weekend effect: moving past proving it exists to clarifying what causes it. In: BMJ Publishing Group Ltd; 2015.

18. Ko SQ, Strom JB, Shen C, Yeh RW. Mortality, length of stay, and cost of weekend admissions. J Hosp Med. 2018;13(7):476-81.

19. Krämer J, Schreyögg J, Busse R. Classification of hospital admissions into emergency and elective care: a machine learning approach. Health Care Manag Sci. 2019;22(1):85-105.

20. Meacock R, Anselmi L, Kristensen SR, Doran T, Sutton M. Higher mortality rates amongst emergency patients admitted to hospital at weekends reflect a lower probability of admission. J Health Serv Res Policy. 2017;22(1):12-9.

21. Myers RP, Kaplan GG, Shaheen AAM. The effect of weekend versus weekday admission on outcomes of esophageal variceal hemorrhage. Can J Gastroenterol Hepatol. 2009:23(7):495-501.

22. Nandyala SV, Marquez-Lara A, Fineberg SJ, Schmitt DR, Singh K. Comparison of perioperative outcomes and cost of spinal fusion for cervical trauma: weekday versus weekend admissions. Spine. 2013;38(25):2178-83.

23. Freemantle N, Ray D, McNulty D, et al. Increased mortality associated with weekend hospital admission: a case for expanded seven day services? Bmj. 2015;351:h4596.

\section{Publisher's Note}

Springer Nature remains neutral with regard to jurisdictional claims in published maps and institutional affiliations.

\section{Ready to submit your research? Choose BMC and benefit from:}

- fast, convenient online submission

- thorough peer review by experienced researchers in your field

- rapid publication on acceptance

- support for research data, including large and complex data types

- gold Open Access which fosters wider collaboration and increased citations

- maximum visibility for your research: over $100 \mathrm{M}$ website views per year

At BMC, research is always in progress.

Learn more biomedcentral.com/submissions 